\title{
Corrigendum: Exogenous Ketone Supplements Reduce Anxiety-Related Behavior in Sprague-Dawley and Wistar Albino Glaxo/Rijswijk Rats
}

\begin{abstract}
Csilla Ari ${ }^{1 *}$, Zsolt Kovács ${ }^{2}$, Gabor Juhasz ${ }^{3}$, Cem Murdun ${ }^{1}$, Craig R. Goldhagen ${ }^{1}$, Andrew P. Koutnik ${ }^{1}$, Angela M. Poff ${ }^{1}$, Shannon L. Kes/ ${ }^{1}$ and Dominic P. D'Agostino ${ }^{1}$

${ }^{1}$ Department of Molecular Pharmacology and Physiology, Hyperbaric Biomedical Research Laboratory, Morsani College of Medicine, University of South Florida, Tampa, FL, USA, ${ }^{2}$ Department of Zoology, University of West Hungary, Szombathely, Hungary, ${ }^{3}$ Proteomics Laboratory, Eotvos Lorand University, Budapest, Hungary
\end{abstract}

Keywords: anxiety, exogenous ketone supplements, ketones, elevated plus maze, animal models

\section{A corrigendum on}

\section{OPEN ACCESS}

Edited and reviewed by: Susan A. Masino,

Trinity College, USA

*Correspondence:

Csilla Ari

csari2000@yahoo.com

Received: 10 January 2017 Accepted: 31 January 2017 Published: 13 February 2017

Citation:

Ari C, Kovács Z, Juhasz G, Murdun C Goldhagen CR, Koutnik AP, Poff AM, Kes/ SL and D'Agostino DP (2017)

Corrigendum: Exogenous Ketone Supplements Reduce Anxiety-Related Behavior in Sprague-Dawley and Wistar Albino Glaxo/Rijswijk Rats.

Front. Mol. Neurosci. 10:36. doi: 10.3389/fnmol.2017.00036
Exogenous Ketone Supplements Reduce Anxiety-Related Behavior in Sprague-Dawley and Wistar Albino Glaxo/Rijswijk Rats

by Ari, C., Kovács, Z., Juhasz, G., Murdun, C., Goldhagen, C. R., Koutnik, A. P., et al. (2016). Front. Mol. Neurosci. 9:137. doi: 10.3389/fnmol.2016.00137

An author name was incorrectly spelled as Andrew M. Koutnik. The correct spelling is Andrew P. Koutnik. The authors apologize for this error and state that this does not change the scientific conclusions of the article in any way. The original article has been updated.

Conflict of Interest Statement: International Patent \# PCT/US2014/031237, University of South Florida, DD, SK, P. Arnold, "Compositions and Methods for Producing Elevated and Sustained Ketosis." P. Arnold (Savind) has received financial support (ONR N000140610105 and N000140910244) from DD (USF) to synthesize ketone esters. Provisional patent \# 16A007, University of South Florida, CA, P. Arnold, DD "Exogenous Ketone Supplements for Reducing Anxiety-Related Behavior."

The other authors declare that the research was conducted in the absence of any commercial or financial relationships that could be construed as a potential conflict of interest.

Copyright (c) 2017 Ari, Kovács, Juhasz, Murdun, Goldhagen, Koutnik, Poff, Kesl and D'Agostino. This is an open-access article distributed under the terms of the Creative Commons Attribution License (CC BY). The use, distribution or reproduction in other forums is permitted, provided the original author(s) or licensor are credited and that the original publication in this journal is cited, in accordance with accepted academic practice. No use, distribution or reproduction is permitted which does not comply with these terms. 